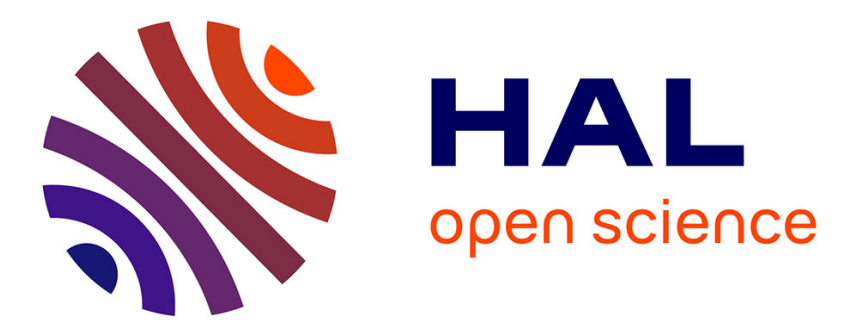

\title{
Reducing information load to enhance collaborative awareness thanks to a pre-selection of information
}

Audrey Fertier, Aurelie Montarnal, Anne-Marie Barthe-Delanoë, Sébastien

Truptil, Frederick Benaben

\section{- To cite this version:}

Audrey Fertier, Aurelie Montarnal, Anne-Marie Barthe-Delanoë, Sébastien Truptil, Frederick Benaben. Reducing information load to enhance collaborative awareness thanks to a pre-selection of information. 19th Working Conference on Virtual Enterprises (PRO-VE), Sep 2018, Cardiff, United Kingdom. p.286-294, 10.1007/978-3-319-99127-6_25 . hal-01885046

\section{HAL Id: hal-01885046 https://imt-mines-albi.hal.science/hal-01885046}

Submitted on 28 Nov 2018

HAL is a multi-disciplinary open access archive for the deposit and dissemination of scientific research documents, whether they are published or not. The documents may come from teaching and research institutions in France or abroad, or from public or private research centers.
L'archive ouverte pluridisciplinaire HAL, est destinée au dépôt et à la diffusion de documents scientifiques de niveau recherche, publiés ou non, émanant des établissements d'enseignement et de recherche français ou étrangers, des laboratoires publics ou privés. 


\title{
Reducing information load to enhance collaborative awareness thanks to a pre-selection of information
}

\author{
Audrey Fertier ${ }^{1}$, Aurélie Montarnal ${ }^{1}$, Anne-Marie Barthe-Delanoë ${ }^{2}$, Sébastien \\ Truptil $^{1}$, Frédérick Bénaben ${ }^{1}$ \\ 1 Centre Génie Industriel - Université de Toulouse - IMT Mines Albi - France \\ 2 Laboratoire de Génie Chimique - Université de Toulouse - CNRS - INPT - UPS - \\ France
}

\begin{abstract}
There is a need for collaboration support systems, suited to crisis management, able to sustain collaborations in ever more unstable environments. The organizations involved in a crisis response need support in limiting information overload by accessing information suited to their current needs. The collaboration support system proposed in this paper uses a Common Operational Picture (COP), supported by a Geographical Information System (GIS), that consists of information selected according to (i) the on-going collaboration phase, and (ii) the level of commitment within the collaboration of the current user. Additionally, to validate the proposed classifications, the paper demonstrates how the pre-selection can be applied to support crisis collaborations, operating under high stress and high information load.
\end{abstract}

Keywords. Collaboration, Crisis management, Common operational picture, Information overload, Model driven engineering

\section{Introduction}

When gathered inside one room, the partners of a collaboration can directly access large amounts of information [10], enabling them to enhance their collaborative awareness. They can identify common goals, critical partners, or share accurate information.

Because the collaborations tend to extend their geographical reach, they cannot gather as easily as before. To help them, 19] recommends the use of a common artifact to support cooperative activities that can be both individually conducted and interdependent. The main goal of the artifact is to reduce the complexity of collaborations, including the complexity of their information system due to:

- The amount of information in our daily lives is continually increasing and is multiplied by existing information systems [11], while our brains can only process a limited amount of complex information; 
- Each partner must be able to access a part of the collaborative awareness adapted to their business and their level of responsibility;

- Information shared within a collaboration comes from heterogeneous sources, and each has an expiration date before which it must be used to not be lost.

These three issues are particularly true during a crisis situation where the collaboration aims to respond to every risk and consequences due to the disaster 20, 15, 12]: the crisis cells have to face high information load and high time pressure, within complex communication channels, while the collaboration can easily breakdown due to heterogeneous experiences, heterogeneous information accesses and heterogeneous comprehensions.

To support the partners in managing the infomration available within the collaboration, we proposed a collaboration support system able to select information according to (i) the on-going collaboration stage and (ii) the level of commitment of the current user, in order to give each user access to a suited Common Operational Picture (COP), supported by a Geographical Information System (GIS).

A COP is, as defined by [16], an operational picture shared by several partners during a particular operation. Its goal is to enables a shared Situation Awareness (SA) within the collaboration. In this case, the term SA can be defined as a model of the environment surrounding the collaboration [9]. This COP can be displayed through the use of a GIS. According to [16], such an information system is a powerful tool to support SA, in particularly during crisis situation where almost all relevant information are spatial.

Our goal is to strengthen collaborative awareness in order to enhance the agility of the collaboration (defined in 2]) in the face of new threats or opportunities. The collaboration support system described in this paper includes:

- A meta-model, as defined by [7], to enable a unified approach of interoperability, and its models modelling the collaborative situation.

- A GIS that takes the shape of a COP to communicate information from the system to the user;

- An automatic classification by collaboration stages to filter information according to the current phase of the collaboration;

- An automatic classification by partner roles to filter the information according to the place of the user in the collaboration.

Section 1 presents the two classifications introduced in this paper: the collaboration classification and the partners classification that are used for the pre-selection stage, to obtain a COP suited to the current stage of the collaboration and to the current user of the system. Section 2 proposes to validate these two classifications by using them in case of a very specific type of collaboration: a crisis collaboration. 


\section{The use of a COP to enhance collaborative awareness}

The Figure 1illustrates how the collaboration support system, proposed in this paper, operates to adapt its COP to is current user and to the current stage of the collaboration.

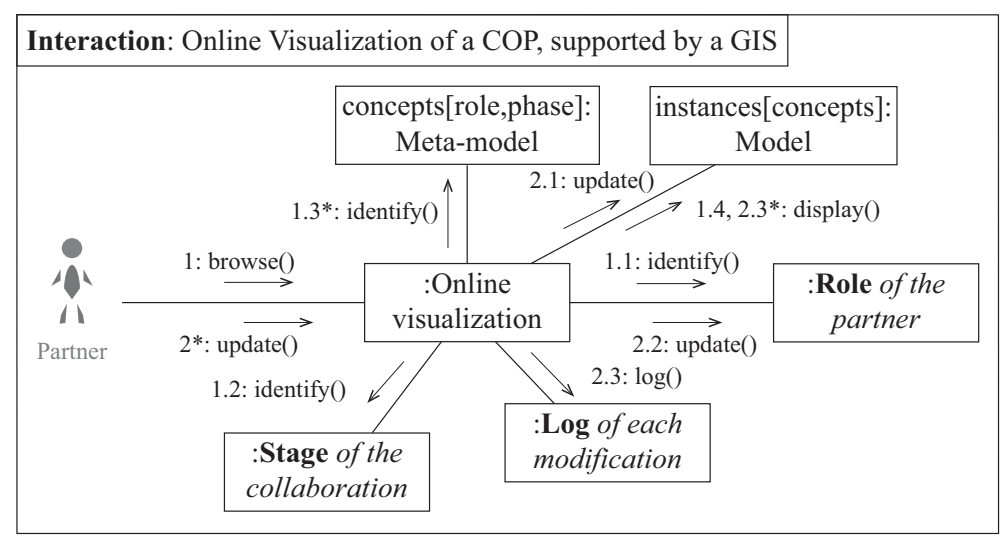

Fig. 1: A communication diagram, in Unified Modelling Language (UML) that illustrates how each partner of a collaboration can use the COP interface of the collaboration support system to enhance their collaborative awareness

The design of the system involves the definition of a meta-model, several partners' roles and several collaboration's stages, that have to be common to every collaboration types:

- The meta-model (defined in [7]) is used to homogenize and organize available information in models. Such a meta-model, dedicated to collaborations, is described in [3];

- The role is used to select information, according to the need of the partner, using the collaboration support system. For example, if a partner manufactures a product for the collaboration benefit, then he needs market forecasts, sub-contractors contact details or warehouses locations. Conversely, he doesn't need customer directories or marketing information.

- The stage is used to select information over time. For example, at the beginning of a new collaboration, the partners need to share their expectations. Conversely, when the collaborative process is running, the partners need to access a list of tasks.

- The logs are stored to enable future improvements of the collaboration support system. 


\subsection{The partners classification to ensure confidentiality}

The work of [21], followed by [5], enabled us to identify three partner roles, inspired from the maturity levels of collaborations and described in Table 1 By default, the system does not share information of higher responsibility levels, with lower responsibility levels:

$$
\begin{aligned}
& \text { A partner } P_{1} \text {, with a role } R_{1} \\
& \text { can reach information shared by a partner } P_{2} \text {, with a role } R_{2} \\
& \text { If only } R_{1} \geq R_{2}
\end{aligned}
$$

Furthermore, during an "update()" operation (cf. Figure 1), a partner can set the default responsibility level of information that he adds to the system. A federated partner can, for example, decide to make its newly added information visible to one, several, or all, open partners.

Table 1: The partners classification by partner roles, defined in this paper

\begin{tabular}{|l|l|}
\hline Role of a partner & Definition of the paper \\
\hline Communicating partner & $\begin{array}{l}\text { A partner that exchanges and shares information with } \\
\text { the collaboration }\end{array}$ \\
Open partner & $\begin{array}{l}\text { A communicating partner that shares business services } \\
\text { andem functionalities with the collaboration } \\
\text { An open partner that takes part in the collaborative pro- } \\
\text { cess, and shares the collaboration's goals }\end{array}$ \\
\hline
\end{tabular}

\subsection{The collaboration classification to filter the displayed information}

Two previous research works [3, 22], have enabled us to identify five main collaboration stages, that are described below in Table 2. Each collaboration stage comes with its own information needs. The table 3 shows how the concepts of one collaboration meta-model (from [3]) can be classified. For example, the partners of a collaboration need to learn about each other at the beginning of the collaboration during the perception stage. Conversely, the goals of the collaboration are set during the convergence stage, when everyone SA is good enough to support this decision.

The classifications are used to identify the "default information" to be first displayed on the $\mathrm{COP}$, for one given user:

If a partner need additional information,

the system does not refer to the collaboration classification,

but only to the partners classification that manage responsibility levels 
Table 2: The collaboration classification by stages, defined in this paper

\begin{tabular}{|l|l|}
\hline Stage of a collaboration & Definition of the paper \\
\hline Perception $(P r)$ & $\begin{array}{l}\text { When each partner gathers information to improve their } \\
\text { situation awareness of the collaboration } \\
\text { When each partner learns how to adapt its information } \\
\text { or its outputs to the other partners } \\
\text { When new information is inferred from the information } \\
\text { shared between several partners } \\
\text { When common goals are identified, solutions are pro- } \\
\text { posed, a solution is chosen and a collaborative process } \\
\text { is designed } \\
\text { When the partners adapt their solution, while the collab- } \\
\text { orative process runs }\end{array}$ \\
\hline
\end{tabular}

Table 3: The concepts of the meta-model [3], labelled with the five collaboration stages, according to their level of usefulness

\begin{tabular}{|c|c|c|c|c|c|c|}
\hline Concepts from [3] & Definition of this paper & $P r$ & $C p$ & $U d$ & $C v$ & $M g$ \\
\hline Partner & A partner of the collaboration & $\bullet$ & - & - & - & - \\
\hline Environment Component & $\begin{array}{l}\text { Anything composing the environ- } \\
\text { ment of the collaboration, that can } \\
\text { be mapped in the COP }\end{array}$ & $\bullet$ & - & - & - & - \\
\hline Characteristic & $\begin{array}{l}\text { Feature due to the nature, the com- } \\
\text { position or the environment of the } \\
\text { collaboration that could generate } \\
\text { opportunities or threats }\end{array}$ & $\bullet$ & - & - & - & - \\
\hline Capacity & $\begin{array}{l}\text { One partner's capability, that can } \\
\text { be used in the collaborative process }\end{array}$ & - & $\bullet$ & $\bullet$ & $\bullet$ & - \\
\hline Objective & A goal of, at least, one of the partner & - & - & $\bullet$ & $\bullet$ & $\bullet$ \\
\hline Performance indicator & $\begin{array}{l}\text { An indicator that measures the per- } \\
\text { formance of one capability, given a } \\
\text { goal }\end{array}$ & - & - & - & $\bullet$ & $\bullet$ \\
\hline Process & $\begin{array}{l}\text { A process that invokes the capabili- } \\
\text { ties of some partner and order them } \\
\text { according to flows of information, } \\
\text { conditions and events }\end{array}$ & - & - & - & - & $\bullet$ \\
\hline Fact & $\begin{array}{l}\text { An event witnessed by, at least, one } \\
\text { of the partner }\end{array}$ & - & - & - & - & • \\
\hline
\end{tabular}

The pair <collaboration stage, user role> enables the generation of a view of the model, suited to the current collaborative situation, in order to feed the COP displayed by the GIS. The Figure 2 shows how the information are selected according to the need of the user. This follows the recommendations of Mica Endsley [?] about goal-directed task analyses. 


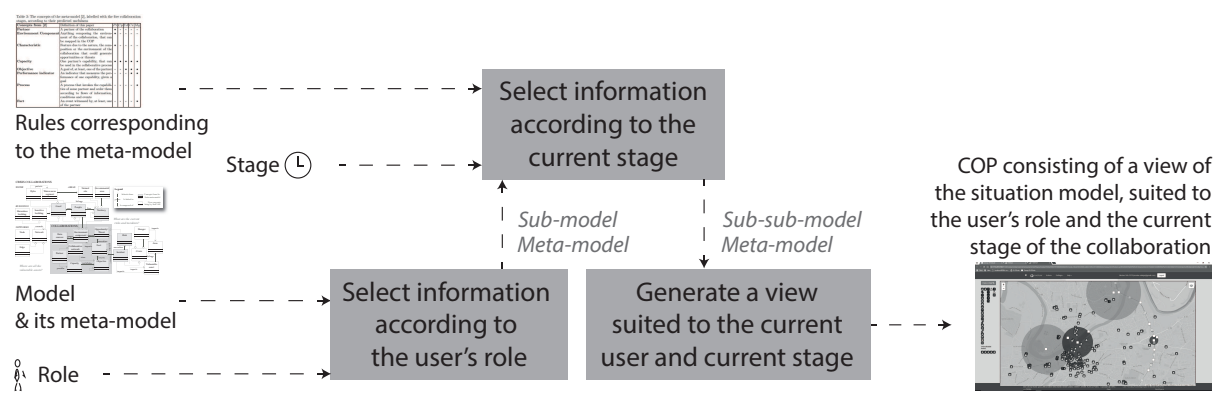

Fig. 2: The process enabling the collaboration support system to generate views suited to both the responsibility level of its user and the current collaboration stage

\section{The case of crisis collaboration}

In the aftermath of a disaster, a crisis response requires the collaboration of numerous, heterogeneous partners, under high stress and high time pressure 18]. This paper unfolds the scenario of a 100-year flood provided by the ANR GéNéPi project 3 . This project had enabled the interview of many practitioners often involved in crisis collaborations. The results, recorded in specifications [17], underlines the issues still faced by practitioners during crisis responses:

- Much of the information available is unclear, outdated or unreliable, and only the partners with high expertise can get by;

- The diagnosis of the impacted territory and the analysis of the vulnerable assets at stake remains difficult;

- Due to the number of partners involved, it's hard to take into account all possibilities of response process, and even harder to find the optimal response process.

The collaboration support system proposed in this paper can support them in dealing with :

- The issues due to the instability of the crisis, thanks to the COP that display the information contains in a model that can be continuously updated, as in 1];

- The issues faced during the understanding phase, thanks to the capacity of the COP to enhance collaborative awareness, as underlined by [4, 6];

- The issues due to information overload thanks to the collaboration and partners classifications, as described in Section 1 .

In order to enable the collaboration support system to generate views of crisis situations, the classifications of collaboration stages and partners' roles dedicated to crisis collaboration still need to be defined.

\footnotetext{
${ }^{3}$ Project ANR-14-CE28-0029, web site
} 


\subsection{The partners classification adapted to crisis collaboration support}

In France, in case of a 100-year flood, the organization involves four different responsibility levels [8]:

- Local level;

- County level;

- Zonal level;

- National level.

The hierarchies in place, corresponding to the crisis partners' roles, impose a dedicated information management. For example, a prefect (county level), aiming to communicate to the press, needs to know about the number of people without electricity supply in the county. Conversely, the power supplier (local level), aiming to ensure the continuity of their network, needs to know the exact locations of cut points on their network.

\subsection{The collaboration classification adapted to crisis collaboration support}

Like the collaboration stages proposed in this paper, several crisis collaboration phases has been defined over time. Among the first to distinct four phases were Uriel Rosenthal and Alexender Kouzmin [18]: "Crises [...] may be considered in terms of circular processes involving mitigation and preparation, response as well as recovery and rehabilitation". Inside the response phase, a french official document [14] recognizes five more phases:

- The confirmation of the alert $(\mathrm{Ca})$ : "Is there a disaster? What is its scale?";

- The alert $(A l)$ : "What are the concerned organisations that will take part in the collaboration?";

- The characterisation of the crisis $(C c)$ : "Where are the assets vulnerable to the consequences of this crisis?";

- The evaluation phase $(E v)$ : "Where are the damaged assets? Where are the threatened assets?";

- The follow-up phase $(\mathrm{Fl})$ that consists of "thoughtful actions" to anticipate long-term consequences.

All the concepts from a meta-model dedicated to collaborative crisis management, as the one described in 3], can be linked to these crisis response phases. The obtained table (an extract is given in Table 4), along with the metamodel from [3], is used by the collaboration support system instead of the Table 2 suited to all kind of collaboration.

Rationally, the links $(\bullet)$ from the links of Table 3 can easily be applied to the crisis concepts of Table 4 because they all inherit from one concept of Table 3 For example, information concerning a new event, useful during the evaluation phase of a crisis, are also useful during the monitoring phase of the collaboration, 
Table 4: Some crisis concepts from [13], labelled with the five crisis response phases from [14], according to their usefulness

\begin{tabular}{|l|l|c|c|c|c|c|}
\hline Crisis concepts from [13] & Parent concept from [3] & $C a$ & $A l$ & $C c$ & $E v$ & $F l$ \\
\hline Danger & Characteristic & $\bullet$ & - & - & - & $\bullet$ \\
Actor & Partner & - & $\bullet$ & - & - & - \\
Good & Environment component & - & - & $\bullet$ & $\bullet$ & - \\
Event & Fact & - & - & - & $\bullet$ & - \\
Response & Process & - & - & - & - & $\bullet$ \\
\hline
\end{tabular}

because an event is considered as a fact.

Thanks to theses new crisis collaboration response phases, and new crisis partners' roles, a collaborative support system, as the one presented in Figure 2. can select the information to be displayed to its user according to their relevance, and therefore decrease information load of the partners involved in a crisis situation.

\section{Conclusion}

This paper offers to use a collaboration support system to display relevant information, via a Common Operational Picture (COP) based on a Geographical Information System (GIS) and describing the collaborative situation.

To further limit information overload and to take into account the different responsibility levels involved, the paper proposes two classifications, dedicated to collaborations:

- The collaboration classification to adapt the COP to the current collaboration stage: either the perception, the comprehension, the understanding, the convergence or the monitoring stage.

- The partners classification to adapt the view to the goal of the current user. It consists of three categories: communicating, open or federated partners.

To extend the proposed classifications, we have checked that these solutions, dedicated to collaborations, apply to crisis collaborations: collaboration in highly unstable environment, under high-stress and time pressure.

\section{Acknowledgements \& Funding sources}

This work would have not been possible without the GéNéPi project research team, or the computer engineers team from the industrial engineering center of IMT Mines Albi. This work was supported by the french National Research Agency, through the GéNéPi project funding (program: Resilience and crisis management [DS0903] 2014; project ID: ANR-14-CE28-0029) 


\section{Bibliography}

[1] Barthe-Delanoë, A.M., Bénaben, F., Carbonnel, S., Pingaud, H.: Event-driven agility of crisis management collaborative processes. In: Proceedings of the 9th International ISCRAM Conference, Vancouver BC, Canada. http://www. iscramlive. org/ISCRAM2012/proceedings/124. pdf (2012)

[2] Barthe-Delanoë, A.M., Truptil, S., Bénaben, F., Pingaud, H.: Eventdriven agility of interoperability during the Run-time of collaborative processes. Decision Support Systems 59, 171-179 (Mar 2014), http://www.sciencedirect.com/science/article/pii/S0167923613002868

[3] Benaben, F., Montarnal, A., Truptil, S., Lauras, M., Fertier, A., Salatge, N., Rebiere, S.: A conceptual framework and a suite of tools to support crisis management. Hawaii (2017), https://scholarspace.manoa.hawaii.edu/bitstream/10125/41178/1/paper0029.pdf

[4] Björkbom, M., Timonen, J., Yiğitler, H., Kaltiokallio, O., García, J.M.V., Myrsky, M., Saarinen, J., Korkalainen, M., Çuhac, C., Jäntti, R., Virrankoski, R., Vankka, J., Koivo, H.N.: Localization Services for Online Common Operational Picture and Situation Awareness. IEEE Access 1, 742-757 (2013)

[5] Bénaben, F.: Conception de Système d'Information de Médiation pour la prise en charge de l'Interopérabilité dans les Collaborations d'Organisations. thesis, Institut National Polytechnique de Toulouse (Oct 2012), https://hal-mines-albi.archives-ouvertes.fr/tel-01206234/document

[6] Bunker, D., Levine, L., Woody, C.: Repertoires of collaboration for common operating pictures of disasters and extreme events. Information Systems Frontiers $17(1), 51-65$ (2015)

[7] Bézivin, J.: On the unification power of models. Software \& Systems Modeling 4(2), 171-188 (May 2005), https://link.springer.com/article/10.1007/s10270-005-0079-0

[8] DSC: Organisation de la réponse de sécurité civile. Tech. rep. (2004)

[9] Endsley, M.R.: Design and evaluation for situation awareness enhancement. In: Proceedings of the Human Factors Society annual meeting. vol. 32, pp. 97-101. SAGE Publications Sage CA: Los Angeles, CA (1988), http://journals.sagepub.com/doi/abs/10.1177/154193128803200221

[10] Jongsawat, N., Premchaiswadi, W.: A Study Towards Improving WebBased Collaboration Through Availability of Group Awareness Information. Group Decision and Negotiation 23(4), 819-845 (Jul 2014), https://link.springer.com/article/10.1007/s10726-013-9349-3

[11] Karlsson, M.: Challenges of Designing Augmented Reality for Military use (2015)

[12] Klein, G., Feltovitch, P., Bradshaw, J., Woods, D.: Common Ground and Coordination in Joint Activity. In: Organizational simulation, vol. 44, pp. 139-185. John Wiley \& Sons (2005), http://www.jeffreymbradshaw.org/publications/Common_Ground_Single.pdf

[13] Lauras, M., Truptil, S., Bénaben, F.: Towards a better management of complex emergencies through crisis management meta-modelling. Disasters 39(4), 687-714 (2015)

[14] Le Cedre: ORSEC Zonal et départemental, disposition spécifique POLMAR/Terre (2015) 
[15] Lee, J., Bharosa, N., Yang, J., Janssen, M., Rao, H.R.: Group value and intention to use - A study of multi-agency disaster management information systems for public safety. Decision Support Systems 50(2), 404-414 (Jan 2011), http://www.sciencedirect.com/science/article/pii/S0167923610001776

[16] Luokkala, P., Nikander, J., Korpi, J., Virrantaus, K., Torkki, P.: Developing a concept of a context-aware common operational picture. Safety Science 93, 277-295 (Mar 2017), http://www.sciencedirect.com/science/article/pii/S0925753516304647

[17] Renou, T., Dolidon, H.: Cahier des charges à l'origine du projet GéNéPi. Tech. rep., CEREMA \& IDETCOM, Loire Moyenne (2015)

[18] Rosenthal, U., Kouzmin, A.: Crises and crisis management: Toward comprehensive government decision making. Journal of Public Administration Research and Theory 7(2), 277-304 (1997), https://academic.oup.com/jpart/article-abstract/7/2/277/957517

[19] Schmidt, K., Simonee, C.: Coordination mechanisms: Towards a conceptual foundation of CSCW systems design. Computer Supported Cooperative Work (CSCW) 5(2-3), 155-200 (1996)

[20] Shen, M., Carswell, M., Santhanam, R., Bailey, K.: Emergency management information systems: Could decision makers be supported in choosing display formats? Decision Support Systems 52(2), 318-330 (Jan 2012), http://www.sciencedirect.com/science/article/pii/S0167923611001552

[21] Touzi, J., Benaben, F., Pingaud, H., Lorré, J.P.: A model-driven approach for collaborative service-oriented architecture design. International Journal of Production Economics 121(1), 5-20 (Sep 2009), http://www.sciencedirect.com/science/article/pii/S0925527309001005

[22] Warner, N., Letsky, M., Cowen, M.: Cognitive Model of Team Collaboration: Macro-Cognitive Focus. Proceedings of the Human Factors and Ergonomics Society Annual Meeting 49(3), 269-273 (Sep 2005), https://doi.org/10.1177/154193120504900312 